\title{
FDG-PET/CT imaging for staging and radiotherapy treatment planning of head and neck carcinoma Letizia Deantonio1 ${ }^{1}$, Debora Beldì1, Giuseppina Gambaro1, Gianfranco Loi², Marco Brambilla ${ }^{2}$, Eugenio Inglese ${ }^{3}$ and Marco Krengli*1
}

\author{
Address: ${ }^{1}$ Radiotherapy, University of Piemonte Orientale "Amedeo Avogadro", Novara, Italy, ${ }^{2}$ Medical Physics, Hospital Maggiore della Carità, \\ Novara, Italy and ${ }^{3}$ Nuclear Medicine, University of Piemonte Orientale "Amedeo Avogadro", Novara, Italy \\ Email: Letizia Deantonio - letizia.deantonio@libero.it; Debora Beldì - deborabeldi@hotmail.com; \\ Giuseppina Gambaro - giusegambaro@alice.it; Gianfranco Loi - gianfrancoloi@libero.it; \\ Marco Brambilla - marco.brambilla@maggioreosp.novara.it; Eugenio Inglese - eugenio.inglese@maggioreosp.novara.it; \\ Marco Krengli* - krengli@med.unipmn.it \\ * Corresponding author
}

Published: 18 September 2008

Radiation Oncology 2008, 3:29 doi:10.1186/1748-717X-3-29

This article is available from: http://www.ro-journal.com/content/3/I/29

(c) 2008 Deantonio et al; licensee BioMed Central Ltd.

This is an Open Access article distributed under the terms of the Creative Commons Attribution License (http://creativecommons.org/licenses/by/2.0), which permits unrestricted use, distribution, and reproduction in any medium, provided the original work is properly cited.
Received: 7 May 2008

Accepted: 18 September 2008

\begin{abstract}
Background: Positron emission tomography (PET) has a potential improvement for staging and radiation treatment planning of various tumor sites. We analyzed the use of $18 \mathrm{~F}$-fluorodeoxyglucose (FDG)-PET/computed tomography (CT) images for staging and target volume delineation of patients with head and neck carcinoma candidates for radiotherapy.

Methods: Twenty-two patients candidates for primary radiotherapy, who did not receive any curative surgery, underwent both CT and PET/CT simulation. Gross Tumor Volume (GTV) was contoured on CT (CT-GTV), PET (PET-GTV), and PET/CT images (PET/CT-GTV). The resulting volumes were analyzed and compared.

Results: Based on PET/CT, changes in TNM categories and clinical stage occurred in 5/22 cases (22\%). The difference between CT-GTV and PET-GTV was not statistically significant $(p=0.2)$ whereas the difference between the composite volume (PET/CT-GTV) and CT-GTV was statistically significant $(p<0.0001)$.
\end{abstract}

Conclusion: PET/CT fusion images could have a potential impact on both tumor staging and treatment planning.

\section{Background}

In squamous cell carcinoma of the head and neck, definitive radiotherapy (RT) provides improved disease control and survival rates through high dose radiation and concurrent administration of systemic drugs. The recent introduction of sophisticated technology, like intensity modulated radiotherapy (IMRT), promises to improve the cost/benefit ratio of therapy further $[1,2]$.
The precise identification of tumor volume remains an open issue: tumor dose escalation and sparing of normal tissue requires a precise identification of the extension of the disease in individual patients. For these reasons, radiation oncologists are interested investigating functional imaging such as positron emission tomography (PET) in particular with ${ }^{18}$ F-fluorodeoxyglucose (FDG) that provides improved staging, treatment response identification, 
and recurrence detection for a wide range of solid cancers $[3,4]$, including head and neck carcinoma $[5,6]$. FDG-PET, however, requires careful correlation with structural images for precise tumor localization because of lack of anatomical information. FDG-PET images can be directly incorporated into CT-based RT planning through a variety of image registration strategies $[7,8]$. This allows radiation oncologists to use the complementary strengths of functional (PET) and structural imaging (CT) co-registered in a single image set.

The purpose of this study was to investigate the potential impact of using PET/CT image fusion for the management of patients with head and neck carcinoma. Specifically, we analyzed how PET/CT may change the clinical stage and the delineation of gross tumor volume (GTV) for radiation treatment planning.

\section{Methods}

\section{Patients characteristics}

Twenty-two consecutive patients with primary head and neck carcinoma were selected for radiotherapy after discussion in multidisciplinary conference and obtaining informed consent following the rules of our institution. Patients with Karnofsky performance status $<80 / 100$, tumor location in the salivary glands or unknown primary site, evidence of distant metastases at initial staging, and need for surgical procedures were excluded from this study. Clinical characteristics of these patients are summarized in Table 1. All patients underwent routine workup including clinical examination, fiber-endoscopy, contrastenhanced CT of the head and neck district, chest X-rays, and liver ultrasound (US). The clinical stage was defined according to the 2002 American Joint Committee on Cancer-International Union Against Cancer (AJCC-UICC) classification [9]. No patients were candidates for curative surgery. Fifteen patients were candidates for combined radiotherapy and platinum-based chemotherapy and 7 patients for radiotherapy alone.

\section{Image acquisition and fusion}

All patients underwent routine CT simulation in supine position, immobilized with head-rest and customized thermoplastic mask by using the scanner GE Prospeed (General Electric, Milwaukee, WI, USA). The planning volume was scanned from the top of the skull to the midthorax. The CT simulation images were subsequently fused to the hybrid PET/CT images by means of a dedicated radiation treatment planning system (RTPS) image fusion tool (Syntegra, Philips Medical System, Eindhoven, The Netherlands) based on a mutual information algorithm.

PET/CT was performed within 5 working days from the CT simulation scan and after at least 21 days from the
Table I: Characteristics of study population.

\begin{tabular}{|c|c|}
\hline Characteristics & $\mathrm{N}$. \\
\hline Patients & 22 \\
\hline \multicolumn{2}{|l|}{ Age (years) } \\
\hline Median & 59 \\
\hline Range & $43-76$ \\
\hline \multicolumn{2}{|l|}{ Gender } \\
\hline Male & 18 \\
\hline Female & 4 \\
\hline \multicolumn{2}{|l|}{ Tumor subsite } \\
\hline Oral Cavity & 2 \\
\hline Oropharynx & 6 \\
\hline Hypopharynx & 6 \\
\hline Larynx & 2 \\
\hline Nasopharynx & 4 \\
\hline Paranasal sinuses & 2 \\
\hline \multicolumn{2}{|l|}{ Histology } \\
\hline Squamous cell & 18 \\
\hline Undifferentiated & 3 \\
\hline Adenocarcinoma & I \\
\hline \multicolumn{2}{|l|}{ Pathologic AJCC stage } \\
\hline I & 4 \\
\hline II & 5 \\
\hline IIB & 2 \\
\hline III & 3 \\
\hline IVA & 7 \\
\hline IVB & I \\
\hline \multicolumn{2}{|l|}{ Pathologic TNM categories } \\
\hline TI, T2, T2b, T3, T4a NO MO & 13 \\
\hline $\mathrm{T} 2, \mathrm{~T} 4 \mathrm{a} \mathrm{NI} \mathrm{MO}$ & 2 \\
\hline T2 N2a MO & I \\
\hline $\mathrm{T} 2, \mathrm{~T} 3, \mathrm{~T} 4 \mathrm{a}$ N2b M0 & 5 \\
\hline T4 N3 Mo & I \\
\hline
\end{tabular}

Abbreviations: AJCC: American Joint Committee on Cancer; $\mathrm{T}$ : tumor extension; N: lymph-nodal disease; M: distant metastasis.

tumor biopsy. In order to assure a reproducible patient setup, the same immobilization device used during CT simulation as well as a flat-panel carbon fiber composite table insert were also used for PET/CT acquisition.

Images were acquired by the Biograph 16 HI-REZ PET/CT scanner (Siemens, Hoffman Estates, IL, USA). The PET component is a high-resolution scanner with a spatial resolution of $4.7 \mathrm{~mm}$ and no septa, thus allowing 3D-only acquisitions. The CT component is the Somatom Sensation sixteen-slice CT (Siemens, Hoffman Estates, IL, USA). The CT scanner is used both for attenuation correction of PET data and for localization of FDG uptake in PET images. All patients were advised to fast for at least 6 hours prior to PET/CT examination. After injection of about 5 MBq of FDG per kg of body weight, patients were rested for a period of about 60 minutes in a comfortable chair. Emission images ranging from the proximal femur to the base of the skull were acquired for 2-3 minutes per bed position. Field of view was of $50 \mathrm{~cm}$ with a matrix of 512 $\times 512$ pixels for CT and of $128 \times 128$ for PET. The proc- 
essed images were displayed in coronal, transverse, and sagittal plans. After image acquisition, PET/CT data sets were sent to the treatment planning system Pinnacle (Philips, Adac Laboratories, Milpitas, CA, USA) through local network.

\section{Tumor staging and target volume delineation}

The clinical staging was analyzed by comparing the PET/ $\mathrm{CT}$ with the CT alone findings. For PET image interpretation, a focal FDG uptake was considered as positive when the activity was significantly above the expected background and could not be explained by a normal structure. A fixed image intensity threshold method (40\% of maximum intensity) was used to outline the PET-GTV for the primary tumor and the involved nodal sites [10].

The target volumes were outlined by two radiation oncologists with specific experience in head and neck tumors management according to the guidelines of the International Commission on Radiation Units and Measurements Report 62 [11]. They were not blinded to each other and outlined together the contours achieving a final consensus. GTVs were contoured on CT images obtaining CT-GTV, PET (PET-GTV), and PET/CT images (PET/CTGTV). The PET/CT-GTV included both PET and CT information. The clinical target volume (CTV), for treatment purpose, was identified as the PET/CT-GTV with an additional $5 \mathrm{~mm}$ margin and included also the regional lymph nodes. The planning target volume (PTV) was subsequently semi-automatically outlined giving an additional $5 \mathrm{~mm}$ margin to the CTV.

For clinical purposes, we always considered the PET image as an additional information to CT image either for tumor staging or for target contouring for treatment planning.

\section{Statistical analysis}

The difference between PET-GTV and CT-GTV and between PET/CT-GTV and CT-GTV were analyzed by Wilcoxon signed rank test. A $p$ value of less than 0.05 was considered to be statistically significant. Data were reported as mean $\pm 95 \%$ confidence interval.

The following additional volumes were considered for the statistical analysis (Figure 1):

-the volume identified by PET but not by CT (PEToutCT), -the volume identified by CT but not by PET (CToutPET), -the common volume of CT and PET (CT\&PET).

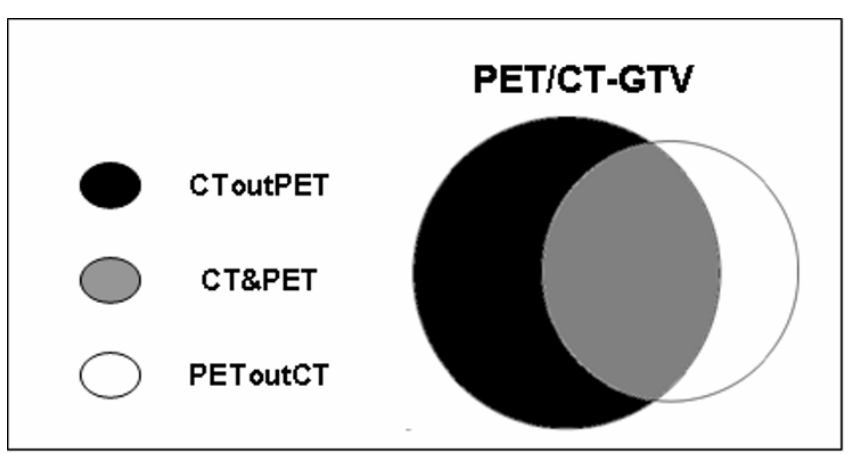

Figure I

The diagram shows the volumes identified after fusion of CT and PET images. "PET/CT-GTV" is the composite volume of PET and CT; "PEToutCT" is the volume identified by PET but not by CT; "CToutPET" is the volume identified by CT but not by PET; "CT\&PET" is the common volume of PET and CT.

\section{Results}

\section{Tumor staging}

PET/CT imaging lead to a change in the TNM categories and in the clinical stage in 5/22 (22\%) cases compared to CT alone (Table 2). T-stage changed in 3 of $22(14 \%)$ and $\mathrm{N}$-stage in 2 of 22 cases (10\%) N0 at CT. In one of these cases (case 3 in Table 2), the PET/CT finding was confirmed by fine needle agobiopsy (FNA). This patient was affected by squamous cell carcinoma of the left hypopharyngeal wall with $1 \mathrm{~cm}$ in diameter lymph node in the left level II had intense FDG uptake suggestive for nodal involvement with potential upstaging from N0 to N1. In such a case, biopsy did not find the presence of tumor cells and the patient was considered as N0. In another case of hypopharyngeal cancer (case 5 in Table 2), a lymph node in the mediastinum, suggestive for metastatic disease, although not confirmed with biopsy by mediastinoscopy because of medical contraindications for general

Table 2: Change of clinical stage related to PET/CT in $\mathbf{5 / 2 2}$ patients (22\%).

\begin{tabular}{|c|c|c|c|}
\hline Case N. & Site & $\mathrm{CT}$ stage & $\mathrm{PET} / \mathrm{CT}$ stage \\
\hline \multirow[t]{2}{*}{ I } & Oropharynx & TI NO MO & T2 NO MO \\
\hline & & Stage I & Stage II \\
\hline \multirow[t]{2}{*}{2} & Nasopharynx & T3 N2b M0 & T4 N2b M0 \\
\hline & & Stage III & Stage IVA \\
\hline \multirow[t]{2}{*}{3} & Hypopharynx & TI NO MO & TI NI MO \\
\hline & & Stage I & Stage III \\
\hline \multirow[t]{2}{*}{4} & Hypopharynx & T2 NO MO & T2 NI MO \\
\hline & & Stage II & Stage III \\
\hline \multirow[t]{2}{*}{5} & Hypopharynx & T3 N2b M0 & T4 N2b MI \\
\hline & & Stage IVA & Stage IVC \\
\hline
\end{tabular}

Abbreviations:

CT: computed -tomography;

PET/CT: positron emission tomography 
anesthesia, was detected by PET/CT. In this case, the clinical stage changed from $\mathrm{M} 0$ to $\mathrm{M} 1$ and consequently the treatment intent from curative to palliative. This patient received radiotherapy combined with chemotherapy and died with intra-thoracic and liver metastases 8 months later.

\section{Target volumes}

As for the volume delineation, PET-GTV was smaller than CT-GTV (17.2 cc, with a standard deviation of $16.8 \mathrm{cc}$ vs. $20.0 \mathrm{cc}$, with a standard deviation of $17.8 \mathrm{cc}$ ) with a mean difference of $2.8 \mathrm{cc}$, that was not statistically significant (p $=0.2)$. However, PET/CT-GTV (26 cc), that was used for clinical purposes, was significantly greater than CT-GTV $(\mathrm{p}<0.0001)$. These volumes had a mean difference of 6 cc (Figure 2). The analyzed volumes for all patients are reported in Table 3.

The mean and range values of the additional volumes analyzed to compare PET/CT and CT alone are reported in Table 4 and Figure 1. In particular, the mean PEToutCT volume was $27 \%$ of the mean CT-GTV and resulted $\geq$ $10 \%$, i.e. $2 \mathrm{cc}$, larger than the mean CT-GTV in $13 / 22$ patients $(59 \%)$.

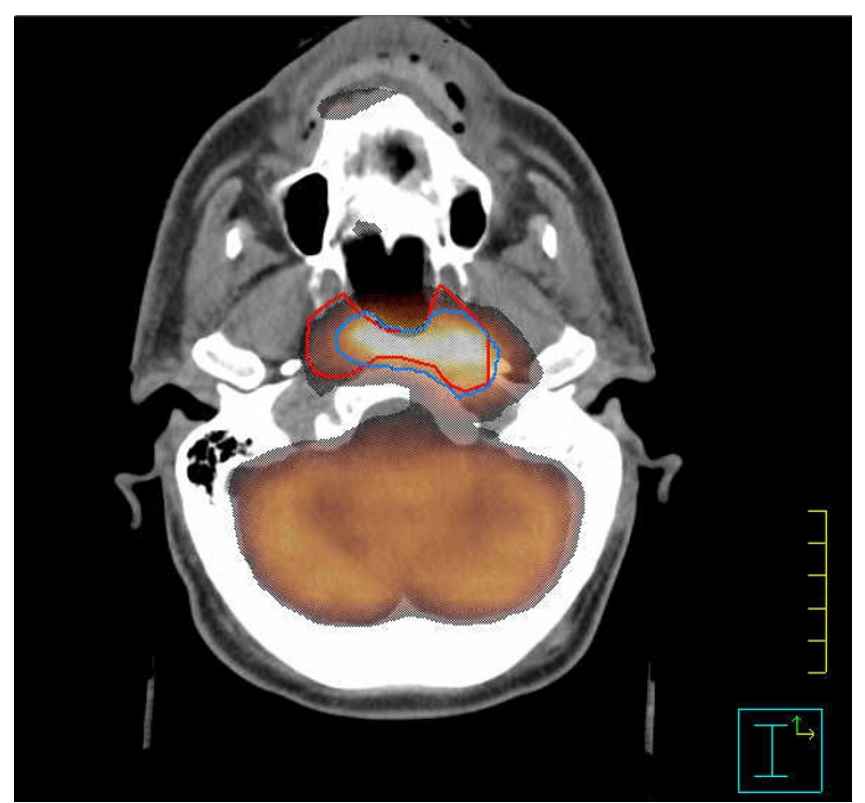

Figure 2

Axial FDG-PET/CT image of a patient with nasopharyngeal undifferentiated carcinoma. The computed tomography gross tumor volume (CT-GTV) and the positron emission tomography (PET)-GTV are highlighted with red and light blue contours, respectively. For treatment purposes both findings were taken into account.
Table 3: Volumes (cc) identified by CT and PET in every single case.

\begin{tabular}{llccc}
\hline Patients & Subsites & CT-GTV & PET-GTV & PET/CT-GTV \\
\hline 1 & Nasopharynx & 17.7 & 30.3 & 36.5 \\
2 & Oral Cavity & 65.9 & 49.0 & 78.7 \\
3 & Oral Cavity & 16.1 & 22.2 & 25.1 \\
4 & Oropharyx & 52.5 & 34.1 & 60.2 \\
5 & Hypopharynx & 5.4 & 1.7 & 5.4 \\
6 & Hypopharynx & 45.5 & 46.3 & 64.2 \\
7 & Hypopharynx & 8.7 & 12.1 & 13.5 \\
8 & Oropharynx & 35.3 & 20.1 & 36.1 \\
9 & Nasopharynx & 6.3 & 3.5 & 6.4 \\
10 & Paranasal sinus & 17.4 & 8.0 & 17.8 \\
11 & Oropharynx & 2.1 & 4.5 & 5.3 \\
12 & Larynx & 9.8 & 1.7 & 9.8 \\
13 & Nasopharynx & 37.0 & 57.8 & 60.3 \\
14 & Oropharynx & 6.0 & 2.6 & 6.2 \\
15 & Oropharynx & 28.9 & 11.2 & 29.4 \\
16 & Oropharynx & 6.5 & 17.3 & 19.8 \\
17 & Hypopharynx & 13.4 & 4.7 & 13.9 \\
18 & Hypopharynx & 1.3 & 4.0 & 5.0 \\
19 & Nasopharynx & 17.8 & 15.2 & 20.3 \\
20 & Paranasal Sinus & 40.8 & 34.7 & 61.8 \\
21 & Hypopharynx & 7.1 & 8.9 & 11.9 \\
22 & Larynx & 19.5 & 6.5 & 19.5 \\
& & & & \\
\hline
\end{tabular}

\section{Discussion}

The use of FDG-PET/CT prior to treatment has gained interest in the radiation oncology community in relation to a potential improvement of tumor staging, optimization of treatment strategy, and better delineation of target volume[12].

The advantage of PET/CT fusion has been already reported for staging and RT planning of non-small cell lung cancer in a number of literature studies [13] and preliminary data on the role of PET/CT fusion are available for other tumor locations such as esophagus, rectum, anal canal, and pancreas [14-16].

Recent results in a limited number of studies are available about the role of PET/CT imaging for staging and RT treat-

Table 4: Volumes (cc) identified after fusion of PET and CT images.

\begin{tabular}{llll}
\hline Volumes & Mean & Range & Confidence Interval \\
\hline PET/CT-GTV & 26.0 & $5.0-78.7$ & $15.9-36.2$ \\
PEToutCT & 5.5 & $0.0-21.2$ & $2.4-8.7$ \\
CToutPET & 8.1 & $0.7-28.0$ & $4.4-11.8$ \\
CT\&PET & 11.2 & $0.4-36.2$ & $6.2-16.2$
\end{tabular}

Abbreviations: PET/CT-GTV: the composite volume between PET and CT; PEToutCT: the volume identified by PET but not by CT; CToutPET: the volume identified by CT but not by PET; CT\&PET: the common volume of the two image modalities (CT and PET). 
ment planning also of patients with head and neck carcinoma [17-20].

In our experience, the primary tumor was identified by PET/CT in all 22 patients with a change for both TNM categories and clinical stage in $22 \%$ of them. Similar results were reported by Koshy and Paulino [21]. In their study, they enrolled 36 patients and found that PET/CT fusion altered the TNM categories in 38\% and the clinical stage in $14 \%$ of the patients. Also in a recent study published by Wang et al. [22], the CT-based staging was changed by PET/CT in $16 / 28$ cases (57\%).

In the second part of our study, we evaluated how PET/CT may influence the delineation of GTV considering the PET information as additional to that of CT. In our experience, the tumor volume identified by PET only was smaller than CT-GTV but the co-registration of PET and CT images allowed the identification of a potentially greater GTV, used for clinical purposes, similarly to what observed by Schwartz et al. [2] in 19 patients. In our series, the PETGTV was smaller than the CT-GTV but the difference (2.8 cc) was not statistically significant $(\mathrm{p}=0.2)$, whereas Heron et al. [18] found a significant decrease $(p=0.002)$ of PET-based GTV compared to CT-based GTV with a median difference of $22.3 \mathrm{cc}$ in a group of 21 patients. Similarly, Paulino et al. [23] observed that PET-GTV was smaller in $75 \%$ of 40 patients, with a median difference between CT-GTV and PET-GTV of $16.9 \mathrm{cc}$. The finding of CT-GTV larger than PET-GTV in our as well as in other published series may be related to areas of necrosis inside the tumor identified by CT but not by PET because of lack of FDG uptake of the necrotic tissue.

A possible criticism to most of these studies, including the present one, is the uncertain correlation of the PET/CT findings with the real tumor extension that can only be precisely assessed on the surgical specimen. In our study, only 1 case had a cytological correlation: PET/CT overestimated the lymph nodal tumor extension. The correlation between tumor delineation on PET compared to pathology was investigated by Halpern et al. [24] who compared FDG-PET/CT image fusion with histopathology on 49 patients. A patient-by-patient analysis yielded a sensibility of $88 \%$, a specificity of $78 \%$, and an accuracy of $86 \%$ for PET/CT compared to pathology. In another study, Daisne et al. [25] compared the GTV identified by PET/CT with the pathology specimen of 9 patients affected by head and neck carcinoma. The investigators observed that the GTV delineated on the pathology specimen was in average smaller than that identified by PET/CT. In particular, PET/ CT underestimated part of the macroscopic tumor extension in the mucosa of the contralateral larynx but, on the other hand, overestimated the infiltration of the cartilage, the extra laryngeal and pre-epiglottic space, and the thyroid gland.

In the article of Daisne et al. [25], the average GTV identified only by PET corresponded to $14 \%$ of the GTV contoured from CT images for oropharyngeal and to $13 \%$ for laryngeal and hypopharyngeal tumor locations. In our study, such value was as high as $27 \%$. This fact should be carefully taken into consideration because the inclusion of this mismatched volume in the target volume could reduce the incidence of geographical missing. This additional volume identified only by PET may have an even greater importance when using highly conformal techniques like intensity modulated radiation therapy (IMRT), stereotactic radiotherapy, and charged particle therapy.

A relevant still open issue is the consistency of target delineation on PET images. In the available literature, GTV contouring with FDG-PET has varied, but has typically been based on standard uptake value (SUV). In the present study, we adopted the $40 \%$ of the SUV similarly to what proposed by other authors for lung and also head and neck tumors $[10,26,27]$.

\section{Conclusion}

The present study shows that FDG-PET/CT images for primary head and neck carcinoma had a potential impact on both tumor staging and treatment planning. A clinical stage variation was observed in $22 \%$ of cases and a significant greater GTV was detected thanks to PET/CT images. Based on our data as well as the other literature results, the future scenario of imaging for radiotherapy of head and neck tumors may include the use of functional imaging such as FDG-PET/CT with the aim to characterize the biological features of the tumor and optimize the use of highly conformal and biologically effective radiation treatment.

\section{Competing interests}

The authors declare that they have no competing interests.

\section{Authors' contributions}

LD is the study coordinator, participated in the development of the study and drafted the manuscript. GL worked on analysis of data, DB, GG, EI and MB participated in the design of the study and are involved in continuing optimization. MK is the study chairman, developed the design of the study, is involved in continuing optimization and helped to draft the manuscript. All authors read and approved the final manuscript.

\section{Acknowledgements}

This work was supported by a grant from the Piedmont Region, Italy in the frame of "Ricerca Sanitaria Finalizzata 2007" 


\section{References}

I. Forastiere A, Koch W, Trotti A, Sidransky D: Head and Neck cancer. N Engl J Med 200I, 345:1890-1900.

2. Schwartz DL, Ford E, Rejendran J, Yueh B, Coltrera MD, Virgin J, Anzai Y, Haynor D, Lewellyn B, Mattes D, Meyer J, Phillips M, Leblanc M, Kinahan P, Krohn K, Eary J, Laramore GE: FDG-PET/CT imaging for preradiotherapy staging of head and neck cell carcinoma. Int J Radiat Oncol Biol Phys 2005, 6 I:I29-I36.

3. Maisey MN: Overview of clinical PET. Br J Radiol 2002, 75:SI-S5.

4. Dizendorf EV, Baumert BG, von Schulthess GK, Lutolf UM, Steinert HC: Impact of whole-body ${ }^{18}$ F-FDG PET on staging and managing patients for radiation therapy. J Nucl Med 2003, 44:24-29.

5. Schechter NR, Gillenwater AM, Byers MR, Garden AS, Morrison WH, Nquyen LN, Podoloff DA, Ang KK: Can positron emission tomography improve the quality of care for head and neck cancer patients? Int I Radiat Oncol Biol Phys 200I, 5 I:4-9.

6. Wong RJ, Lin DT, Schoder H, Patel SG, Gonen M, Wolden S, Pfister DG, Shah JP, Larson SM, Kraus DH: Diagnostic and prognostic value of $[($ I 8)F] fluorodeoxyglucose positron emission tomography for recurrent head and neck squamous cell carcinoma. J Clin Oncol 2002, 20:4199-4208.

7. Rosenman JG, Miller EP, Tracton G, Cullip TJ: Image registration: an essential part of radiation therapy treatment planning. Int J Radiat Oncol Biol Phys 1998, 40:197-205.

8. Slomka PJ, Dey D, Przetak C, Aladl UE, Baum RP: Automated 3dimensional registration of stand-alone (I8)F-FDG whole body PET with CT. I Nucl Med 2003, 44: I I 56- I I 67.

9. Fleming ID, Cooper JS, Henson DE, for the American Joint Committee on Cancer, et al.: AJCC cancer staging manual 6th edition. New York: Springer; 2002.

10. Erdi EE, Mawlawi O, Larson SM, Imbraco M, Yeung H, Finn R, Humm $\mathrm{L}$ : Segmentation of lung lesion volume by adaptive positron emission tomography image thresholding. Cancer 1997, I 2:2505-2509.

II. International Commission on Radiation Units and Measurements: ICRU report 62. Prescribing, recording, and reporting photon beam therapy (supplement to ICRU report 50). Bethesda, MD: ICRU; 1999.

12. Paulino AC, Thorstad $\mathrm{WL}$, Fox $\mathrm{T}$ : Role of fusion in radiotherapy treatment planning. Semin Nucl Med 2003, 33:238-2343.

13. Erdi YE, Rosenzweig K, Erdi AK, Macapinlac HA, Hu YC, Braban LE, Humm JL, Squire OD, Chui CS, Larson SM, Yorke ED: Radiotherapy treatment planning for patients with non-small cell lung cancer using PET. Radiother Oncol 2002, 62:5 I-60.

14. Van Baardwijk A, Baumert B, Bosmans G, Bosmans G, van Kroonenburgh M, Stroobants S, Gregoire V, Lambin P, De Ruysscher D: The current status of FDG-PET in tumour volume definition in radiotherapy treatment planning. Cancer Treat Rev 2006, 32:245-260.

15. Pakzad F, Groves A, Ell P: The Role of Positron Emission Tomography in the Management of Pancreatic Cancer. Semin Nucl Med 2006, 36:248-256.

16. Bassi MC, Turri L, Sacchetti G, Loi G, Cannello B, La Mattina P, Brambilla M, Inglese E, Krengli M: FDG-PET/CT imaging for staging and target volume delineation in preoperative conformal radiotherapy of rectal cancer. Int J Radiat Oncol Biol Phys 2008, 70:1423-1426

17. Nishioka T, Shiga T, Shirato H, Tsukamoto E, Tsuchiya K, Kato T, Ohmori K, Yamazaki A, Aoyama H, Hashimoto S, Chang T, Miyasaka $\mathrm{K}$ : Image fusion between FDG-PET and MRI/CT for radiotherapy planning of oropharyngeal and nasopharyngeal carcinomas. Int J Radiat Oncol Biol Phys 2002, 53:105 I- 1057.

18. Heron DE, Andrade RS, Flickinger J, Johnson J, Agarwala SS, Wu A, Kalnicki S, Avril N: Hybrid PET/CT simulation for radiation treatment planning in head and neck cancers: a brief technical report. Int J Radiat Oncol Biol Phys 2004, 60:|4| 9-|424.

19. Riegel AC, Berson AM, Destian S, Nq T, Tena LB, Mitnick RJ, Wong PS: Variability of gross tumor volume delineation in head-and neck cancer using CT and PET/CT fusion. Int J Radiat Oncol Biol Phys 2006, 65:726-732.

20. Breen SL, Publicover J, De Silva S, Pond G, Brock K, O'Sullivan B, Cummings B, Dawson L, Keller A, Kim J, Ringash J, Yu E, Hendler A, Waldron J: Intraobserver and interobserver variability in GTV delineation on FDG-PET-CT images of head and neck cancers. Int J Radiat Oncol Biol Phys 2007, 68:763-770.
21. Koshy M, Paulino AC, Howell R, Schuster D, Halkar R, Davis LW: FI 8FDG-PET/CT fusion in radiotherapy treatment planning for head and neck cancer. Head and Neck 2005, 27:494-502.

22. Wang D, Schultz CJ, Jursinic PA, Bialkowski M, Zhu XR, Brown WD Rand SD, Michel MA, Campbell BH, Wong S, Li XA, Wilson JF: Initial experience of FDG-PET/CT guided IMRT of head and neck carcinoma. Int J Radiat Oncol Biol Phys 2006, 65:|43-I5I.

23. Paulino AC, Koshy M, Howell R, Schuster D, Davis LW: Comparison of CT and FDG-PET -defined gross tumor volume in IMRT for head and neck cancer. Int J Radiat Oncol Biol Phys 2005, 6 I : I385-1392.

24. Halpern BS, Yeom K, Fueger BJ, Lufkin RB, Czernin J, Allen-Aurbach $M$ : Evaluation of suspected local recurrence in head and neck cancer: a comparison between PET and PET/CT for biopsy proven lesions. Eur J Radiol 2007, 62:199-204.

25. Daisne JF, Duprez T, Weynand B, Lennoux M, Hamoir M, Reychler H, Gregoire $V$ : Tumour volume in pharyngolaryngeal squamous cell carcinoma: comparison at CT, MR imaging and FDG PET and validation with surgical specimen. Radiology 2004, 233:93-100.

26. Ford EC, Kinahan PE, Hanlon L, Alessio A, Rejendran J, Schwartz DL, Phillips $M$ : Tumor delineation using PET in head and neck cancers: threshold contouring and lesion volumes. Med Phys 2006 , 33:4280-4288.

27. Black QC, Grills IS, Kestin LL, Wong CO, Wong JW, Martinez AA, Yan D: Defining a radiotherapy target with positron emission tomography. Int J Radiat Oncol Biol Phys 2004, 60: I 272- 1282.
Publish with Bio Med Central and every scientist can read your work free of charge

"BioMed Central will be the most significant development for disseminating the results of biomedical research in our lifetime. "

Sir Paul Nurse, Cancer Research UK

Your research papers will be:

- available free of charge to the entire biomedical community

- peer reviewed and published immediately upon acceptance

- cited in PubMed and archived on PubMed Central

- yours - you keep the copyright

Submit your manuscript here:

http://www.biomedcentral.com/info/publishing_adv.asp
BioMedcentral 